\title{
Gasification of High and Low Density Crop Residues
}

\author{
Amit Kumar Singh Parihar, Vinayak B. Kulkarni and G. Sridhar
}

\section{Siemens Technology and Services Pvt. Ltd., Corporate Research and Technologies, Bangalore, India}

\begin{abstract}
Crop residue constitutes a large fraction of biomass particularly in agricultural based economies like India. The most abundantly generated crop residues are paddy husk, paddy straw, coconut shell, cotton stalk and sugar cane trash. It is estimated that the potential of power generation using crop residue is close to $14 \mathrm{GWe}$ in a country like India. Even though the potential is large, the main drawback with crop residue is that it is sparsely distributed and being of low density causes collection and transportation problem. This drawback could be converted into an advantage by adopting distributed power generation technologies. The distributed power generation would fare well in the power range of few hundred kilowatts and the most appropriate technology would be the biomass gasification technology. Among the biomass gasification technologies, the downdraft technology is ideally suited for power generation. The downdraft technology is proven with solid or woody biomass, whereas there are limitations in terms of acceptance of all types of crop residues. In this paper, performance study of two vastly differing crop residues, namely coconut shell and cotton stalk has been discussed; both the feedstocks have been tested in "post-harvested" condition with minimum amount of pre-processing. The performance with cotton stalk was found to be comparable at part load; however at higher load the gas composition deteriorated due to poor material movement within the reactor. This had implication in terms of maximum power generated. There was loss of power to an extent of $12 \%$. The operational issues with post-harvested cotton stalk has been brought out which are based on detailed measurements.
\end{abstract}

Keywords: Biomass Gasification, Crop Residue, Cotton Stalk, Coconut Shells.

\section{INTRODUCTION}

Crop residue constitutes a large fraction of biomass particularly in agricultural based economies like India. Some of the most abundantly generated crop residues are paddy husk, paddy straw, coconut shell, cotton stalk and sugar cane trash. It is estimated that the potential of power generation using surplus crop residue is about 14 GWe in a country like India [1]. Among the crop residues, the annual generation of surplus cotton stalk is about 13 - 17 million tonnes [1, 2], which has a power potential of 1.6 - 2 GWe. Even though the potential is large, the main drawback with crop residue is that it is sparsely distributed and largely being light in weight causes collection, transportation and storage problems.

Crop residue gets generated in one or two stages depending upon the type of crop. The first stage of generation, which can be called as primary residue, happens in the farm as a consequence of crop harvest. The crop residue that is generated in this process is largely burnt in the farm as it does not fetch additional revenue to the farmers (other than a small fraction which is used as animal feed and fuel for cooking). The second stage of generation, which can be called as secondary residue, happens at local rural industries, for instance in rice and coconut mills, wherein paddy and coconut are processed. The residue of such post

${ }^{*}$ Address correspondence to this author at the Siemens Technology and Services Pvt. Ltd., Corporate Research and Technologies, Bangalore, India; Tel: +91 (80) 33132271; E-mail: srigrao14@gmail.com processing activity i.e rice husk and coconut shells is available at such local industries for further usage. It is the primary residue which largely goes unutilized and needs to be addressed as it provides scope for power generation. Considering that it is challenging to handle lighter crop residue in large quantities, the possibility of using crop residue in smaller quantities needs to be explored. This of course calls for adaptation of right technologies. One such route is the gasification technology, which is most appropriate for distributed power generation application. The distributed power generation would typically fit in the power range of few hundred kilowatts and appropriate to serve end requirement such as rural electrification.

Coming to the crop residue, it is interesting to state that there is huge diversity in its physical properties form, size and density. All these properties influence its behavior in thermo-chemical conversion process such as combustion or gasification. For instance the particle density can vary as high as $1100 \mathrm{~kg} / \mathrm{m}^{3}$ for coconut shells to as low as $50 \mathrm{~kg} / \mathrm{m}^{3}$ for rice husk [1]. It is this heterogeneity which throws a huge challenge and also an opportunity for innovative research. One method of overcoming this drawback is by resorting to homogenizing by densification or compaction of crop residue [2, 3]. However, not all crop residues would require densification; there could be threshold value of density up to which crop residue could be used in postharvested condition, provided they are sized to the requirement and sun dried. The effect of density on material movement in the gasification process is well captured in the literature $[1,4]$. 
Among the biomass gasification technologies it is well known that downdraft technology is ideally suited for power generation $[1,4]$. The downdraft technology has been proven for woody and briquetted biomass [1, 4] whereas there are limitations in terms of acceptance of crop residue in post-harvested condition. In this paper a comparative study of the behavior of two vastly different crop residues, namely coconut shell and cotton stalk is discussed. Both the feedstocks have been used in post-harvested condition with minimum amount of pre-processing (sizing). The sizing was done at the supplier's end and processed biomass was supplied for testing purpose. In both cases the gasified fuel gas i.e. producer gas was supplied to a gas engine and its performance was evaluated. The metrics for comparison is gas quality - calorific value, particulate and tar level, gasification efficiency, specific fuel consumption and emissions. The operational issues and limitations in performance with cotton stalk are brought out.

\section{FEEDSTOCK DETAILS}

The performance characterization of two feedstocks has been discussed. One of them being broken coconut shell, whose dimension ranged between 25 $\mathrm{mm}$ and $60 \mathrm{~mm}$, and the other being low density cotton stalk. Cotton stalk as shown in Figure 1, measured a minimum diameter of $6 \mathrm{~mm}$ to a maximum of about 25 $\mathrm{mm}$ and about $50 \mathrm{~mm}$ length. The average bulk density of coconut shell and cotton stalk was found to be 400 $425 \mathrm{~kg} / \mathrm{m}^{3}$ and $190-210 \mathrm{~kg} / \mathrm{m}^{3}$ respectively. Therefore in terms of bulk density, the variation between the two feedstocks is more than 2. Bulk density would influence the material movement within the gasifier reactor and thereby have implication on the performance.

The properties of the biomass - proximate, ultimate and calorific value of the fuel is shown in Table 1. It is evident that the ash content in cotton stalk is higher than coconut shell but due to higher $\mathrm{H} / \mathrm{C}$ ratio, the calorific value of cotton stalk is higher by about $20 \%$. The higher ash content with cotton stalk provided necessary indication on how to set the rate of ash extraction during the gasification process so as to maintain the reactor pressure below acceptable levels i.e. $-1200 \mathrm{~Pa}$.

\section{TEST DETAILS}

Both the feedstocks were subjected to trials in the twin air entry; downdraft re-burn biomass gasifier system $[1,4,6]$. This reactor technology is proven to provide a more uniform thermal profile by the virtue of distributed air supply and thereby ensures elimination of most of the tar within the reactor [1,4]. The gas conditioning system is comprised of a hot cyclone, scrubbers and fabric filter $[1,4,6]$. The hot cyclone removes the large particulate matter, scrubbers cool and clean the gas off the contaminants and finally the fabric filter removes the residual contaminants. Multiple trials were carried out at varying load or throughput (50, 75 and $100 \%$ ). The system was essentially operated in a manner where the producer gas generated from the gasifier is fed to a gas engine for power generation. The gas engine is coupled to a 3-phase AC generator and the power generated by the system was measured in terms of electrical power output in all the trials. The specification of the gas engine generator is given in Table 2. The trials were carried at laboratory conditions and parameters related to gasifier and gas engine were monitored. Tests were conducted primarily at loads as mentioned above, for each of feedstock, for 8 to 10 hour duration and all relevant parameters related to gasifier and engine performance were recorded. Furthermore, these results are benchmarked against norms of MNRE (Ministry for New and Renewable Energy), Govt. of India [7]. The biomass gasification
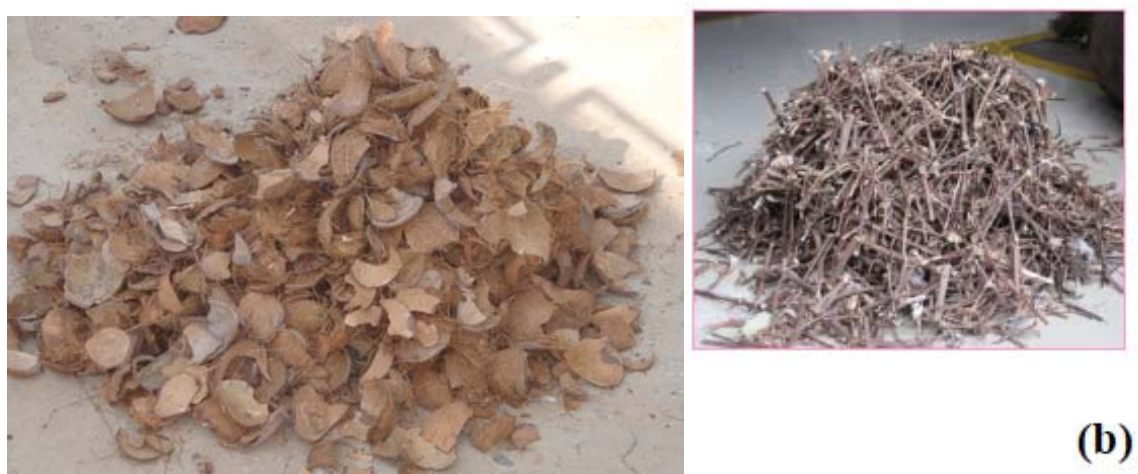

(b)

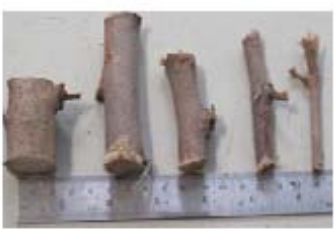

(a)

Figure 1: (a) Coconut Shells and (b) Cotton Stalks. 
Table 1: Fuel Analysis

\begin{tabular}{|c|c|c|c|c|c|}
\hline S.No. & Parameters & \multicolumn{2}{|c|}{ Results } & & \\
\hline \multicolumn{6}{|l|}{$\mathbf{I}$} \\
\hline & \multicolumn{5}{|c|}{ Proximate Analysis, \% by wt., (as-received basis) IS: 1350} \\
\hline & Feedstock & \multicolumn{2}{|c|}{ Coconut shell } & \multicolumn{2}{|c|}{ Cotton stalk } \\
\hline 1 & Moisture & \multicolumn{2}{|c|}{5.87} & \multicolumn{2}{|c|}{3.98} \\
\hline 2 & Ash & \multicolumn{2}{|c|}{0.66} & \multicolumn{2}{|c|}{2.51} \\
\hline 3 & Volatile Matter & \multicolumn{2}{|c|}{78.82} & \multicolumn{2}{|c|}{81.89} \\
\hline 4 & Fixed Carbon & \multicolumn{2}{|c|}{14.65} & \multicolumn{2}{|c|}{11.62} \\
\hline \multirow[t]{2}{*}{ II } & \multicolumn{5}{|c|}{ Ultimate Analysis, \% wt. IS: 1350} \\
\hline & & As-Received Basis & Dry Basis & As-Received Basis & Dry Basis \\
\hline 1 & Ash & 0.62 & 0.66 & 2.51 & 2.61 \\
\hline 2 & Carbon & 41.61 & 44.2 & 40.48 & 42.16 \\
\hline 3 & Hydrogen & 4.74 & 4.35 & 5.81 & 6.05 \\
\hline 4 & Nitrogen & 0.44 & 0.47 & 0.35 & 0.36 \\
\hline 5 & Sulphur & 0.085 & 0.09 & 0.51 & 0.53 \\
\hline 6 & $\begin{array}{c}\text { Oxygen } \\
\text { (By Difference) }\end{array}$ & 52.5 & 50.23 & 50.34 & 48.29 \\
\hline III & Gross Calorific Value, MJ/kg & 15.00 & 15.94 & 17.99 & 18.73 \\
\hline IV & Net Calorific Value, MJ/kg & 13.95 & 14.97 & 16.69 & 17.39 \\
\hline
\end{tabular}

system which qualifies the norms is eligible to apply for federal government subsides under various gasifier dissemination programmes. The major qualifying norms comprise of parameters such as producer gas calorific value, gas quality in terms of particulate matter and tar, and specific biomass consumption or overall efficiency. In brief the qualifying norms of a biomass gasifier coupled with a naturally aspirated gas engine [7] are as follows: Cold gasification efficiency - 70\%; Particulate matter in clean gas - $50 \mathrm{mg} / \mathrm{Nm}^{3}$; Tar in clean gas - $100 \mathrm{mg} / \mathrm{Nm}^{3}$; specific fuel consumption (sfc) at $12 \%$ moisture $-1.8 \mathrm{~kg} / \mathrm{kWh}$.

A typical test protocol that was adopted is shown in Figure 2. This essentially represents the events occurring over a complete time span of a given trial. After the gasifier stabilization in flare mode, the producer gas engine generator was started using the in-situ generated producer gas and gradually the load on the gas engine generator was increased to the reach the target load within a time span of one hour or so. Later, the system operation was continued at constant load and the reactor gas exit temperature was continuously monitored. This was done in order to arrive at the steady state condition. The condition for identifying the steady state would be that the reactor exit temperature doesn't fluctuate beyond $5 \%$ over a time period of 30 minutes. Typical time period to achieve steady state varied between 2 to 3 hours. Once the steady state was achieved, the gas quality measurements were initiated (sampling of gas for Particulate Matter and Tar) at raw and clean gas ends.

After the completion of Particulate Matter \& Tar sampling, the load on the gas engine generator was reduced and switched off. During the complete trial, all the important parameters related to gasifier such as biomass consumption, pressures, temperature, gas flow rate and gas composition were recorded periodically. The mass flow rate of producer gas, static pressure and temperature were measured using calibrated orifice plate, pressure transducer/manometer and thermocouples respectively. Similarly the char and ash collected in the bins were collected and weighed. The heating value of the char was found by conducting calorific value test on the extracted char sample.

The producer gas composition was analyzed using a individual component/species analyzers comprising of hydrogen $\left(\mathrm{H}_{2}\right)$, carbon monoxide $(\mathrm{CO})$, methane $\left(\mathrm{CH}_{4}\right)$, carbon dioxide $\left(\mathrm{CO}_{2}\right)$ and oxygen $\left(\mathrm{O}_{2}\right)$ detecting sensors. The measurements of $\mathrm{CO}, \mathrm{CH}_{4}$ and $\mathrm{CO}_{2}$ fractions are based on NDIR (Non Dispersive Infrared) technique, $\mathrm{H}_{2}$ on thermal conductivity technique and 


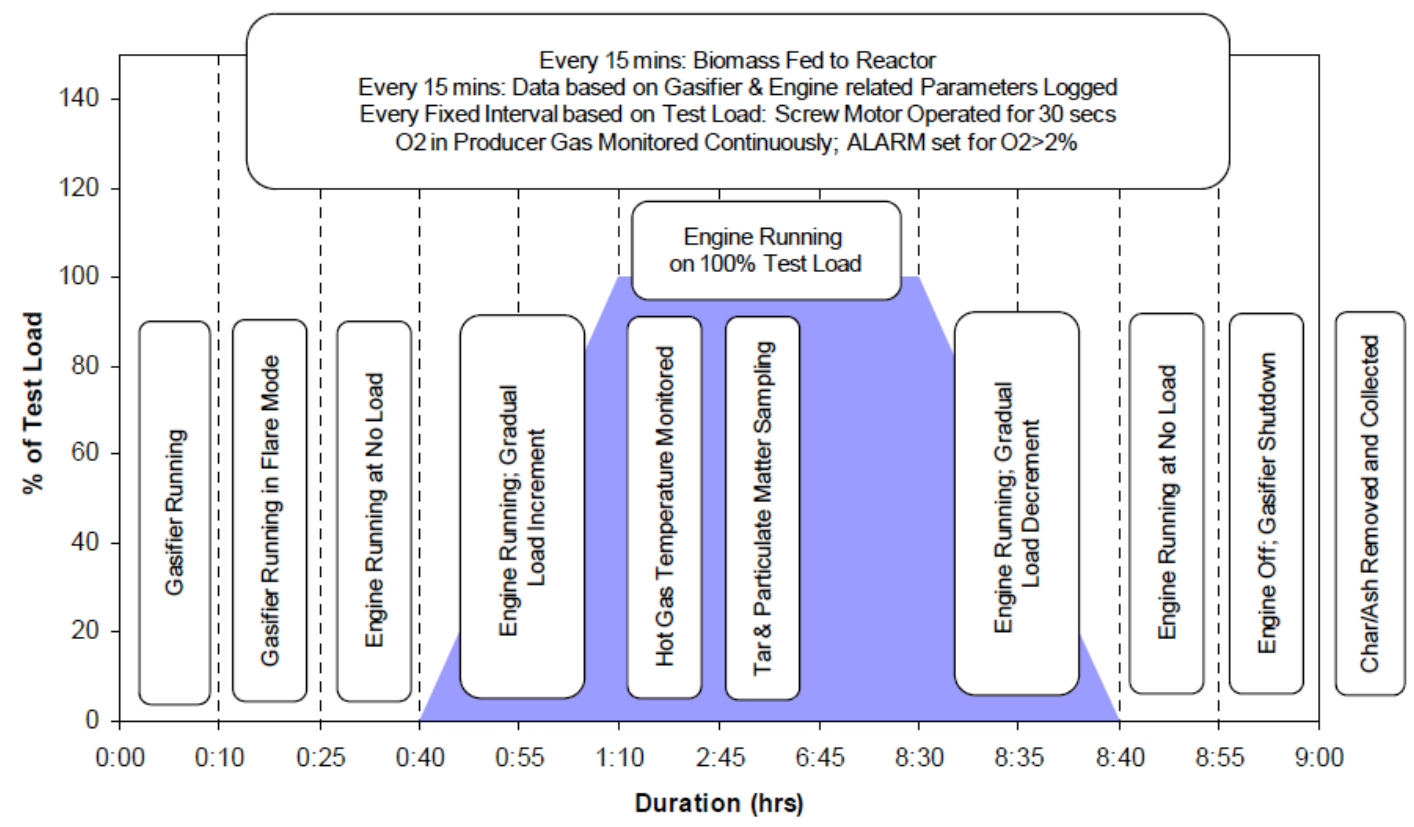

Figure 2: Typical Test Procedure.

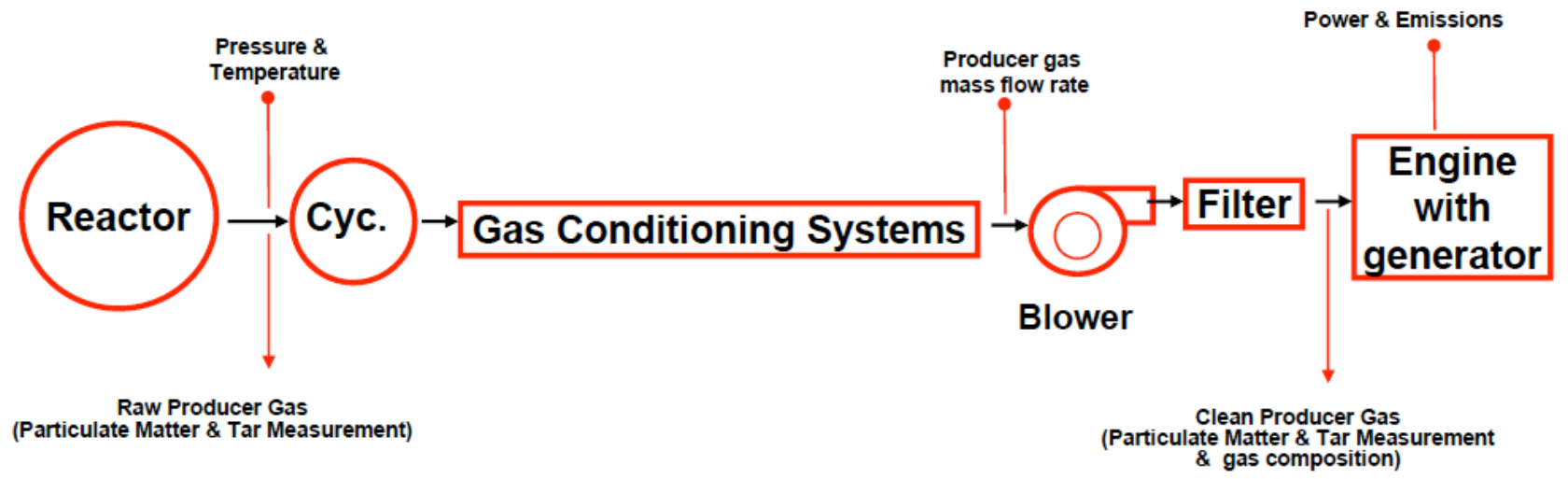

Figure 3: Schematic of the Experimental Test Set-up.

the $\mathrm{O}_{2}$ on paramagnetic cell. Similarly the producer gas was sampled for particulate matter and tar continuously for duration of four hours, both at reactor exit (raw producer gas) and entry to the gas engine (clean producer gas) ends simultaneously as shown in Figure 2. This was done using the well established procedure for Particulate matter and Tar sampling procedure identified by MNRE for gasifier qualification [7]. Similarly on the gas engine part, the power output and emissions were recorded. The flue gas composition was analyzed using a multi-component analyzer, which are based on infrared and chemical cell technique. The species analyzed were nitrogen oxide (NO), carbon monoxide $(\mathrm{CO})$, carbon dioxide $\left(\mathrm{CO}_{2}\right)$, sulphur dioxide $\left(\mathrm{SO}_{2}\right)$ and oxygen $\left(\mathrm{O}_{2}\right)$ on an intermittent basis. Since the fuel used was clean gas therefore particulate matter in the exhaust gas was not measured.

\subsection{Summary on Trials with Coconut Shell}

Trials with coconut shell were smooth and the gas engine consistently delivered a peak power output of $25 \mathrm{kWe}$. The pressure drop across the reactor was well within the design limits of $-800 \mathrm{~Pa}$, as shown in Figure 4. Also the material movement within the reactor was smooth; this is based on visual observation. This observation is based on multiple trials carried out for each load in order to establish repeatability and reproducibility in the outcome of the trial.

\subsection{Summary on Trials with Cotton Stalk}

Trials with cotton stalk were successful, a peak power output of $22.0 \mathrm{kWe}$ was attained against a rated power output of $25 \mathrm{kWe}$ of gasifier + engine system using coconut shell. This corresponds to about $88 \%$ of 


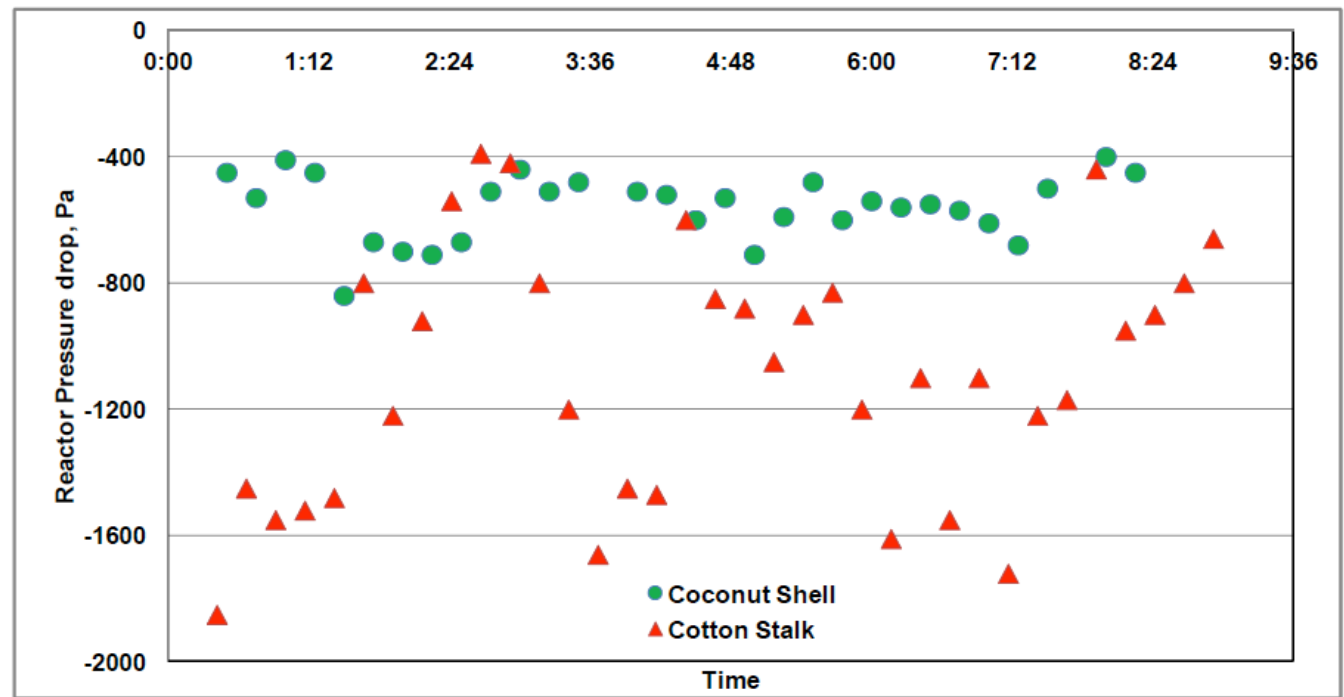

Figure 4: Comparison of Reactor Pressure Drop at Maximum Load.

rated power output of the system. The shortfall of power output was due to reactor pressure drop going high, beyond permissible or allowable limits (more than - $1200 \mathrm{~Pa}$ ) as shown in Figure 4. This happened even though the char/ash extraction was set on a higher side during the operation of the system. The reason for reactor pressure drop going high was due to clinker formation within the reactor, which became evident during post test inspection.

One other problem faced with cotton stalk was the poor material movement within the reactor. This lead to bridging thereby forming void/gaps inside the reactor; this in turn provided opportunity for local burning of gas (along with air drawn through the air nozzle) within the reactor thus resulting in higher gas temperature exiting the reactor. This is evident from Figure $\mathbf{5}$ which compares the reactor exit temperature for the two feedstocks. As it can be observed, the reactor exit temperature is higher with cotton stalk by almost $50^{\circ} \mathrm{C}$. This occurred as a result of void spaces that got formed within the reactor due to poor flow-ability or bridging, thereby causing poor packing density of charge within the reactor. Within these void spaces some of the combustible gas species burned thus leading to increase in gas exit temperature and also loss of energy content or calorific value of the producer gas. This issue was overcome to some extent by resorting to periodical poking or disturbing biomass from the reactor top. But considering the typical duty cycle of gasifier for field operations, it is imperative to adopt a mechanized or motorized poking mechanism to assist the material movement whenever low bulk density feedstock such as cotton stalk is employed.

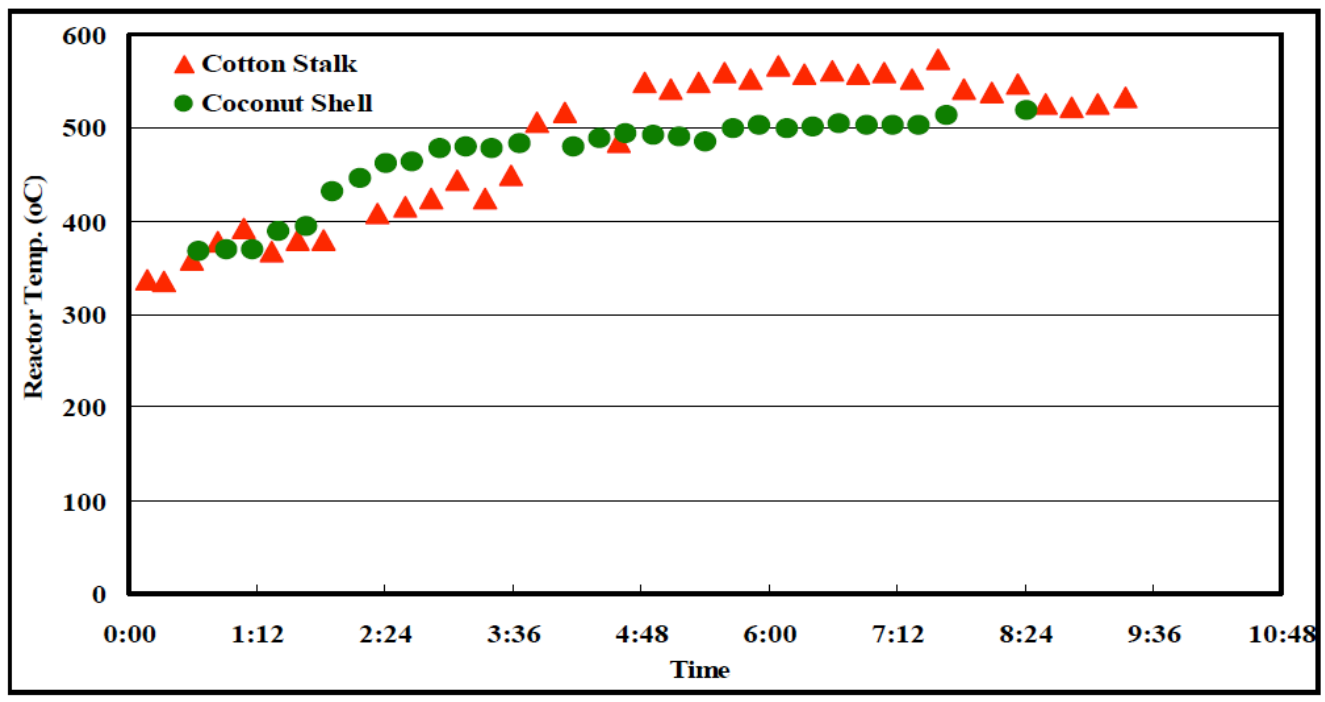

Figure 5: Comparison of Reactor Exit Temperature at Maximum Load. 


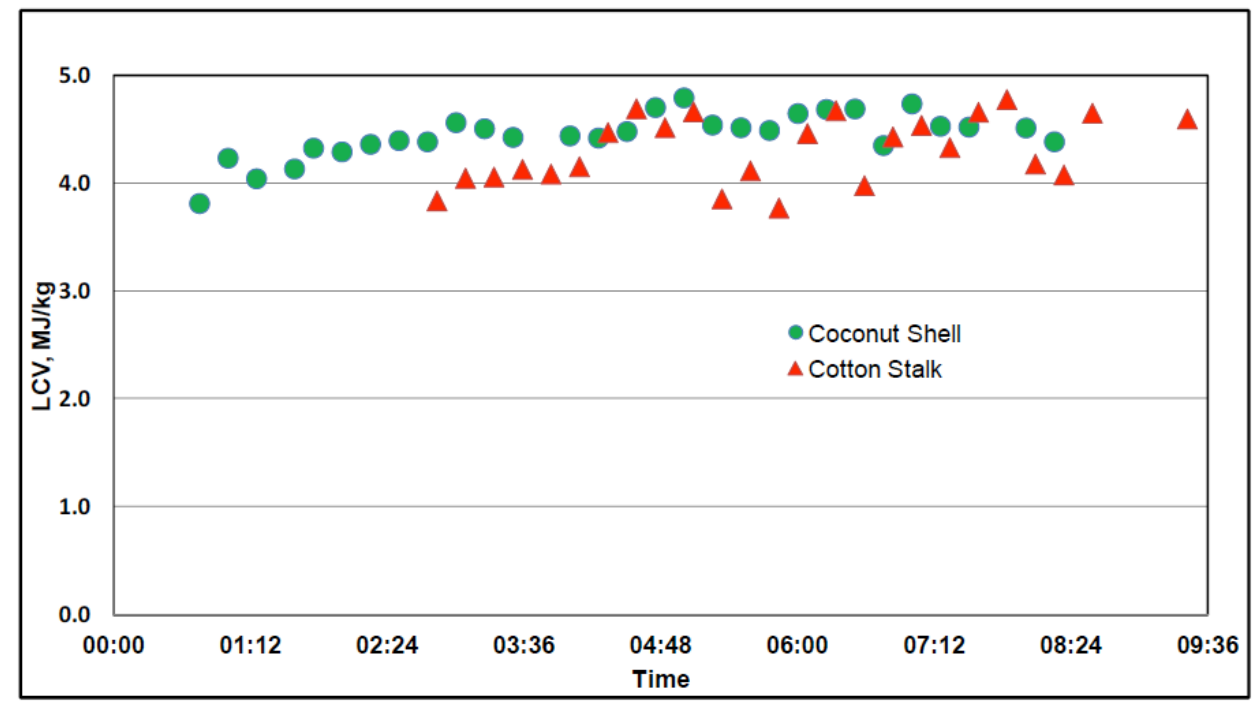

Figure 6: Comparison of LCV of Producer Gas at Maximum Load.

\section{TEST RESULTS}

The post-test analysis involved analyzing the data of gasifier and engine related parameters. As mentioned earlier, there are three important parameters qualifying the gasifier performance, firstly, the cold gasification efficiency, which is essentially the ratio of net energy available in the cold gas to the energy content in the biomass. The second parameter is the specific biomass consumption or the overall efficiency - this represents the biomass-to-electricity conversion efficiency. The third parameter is related to the particulate and tar content in the cold gas, prior to the entry to the engine. As indicated earlier the test results based on the above parameters were benchmarked against the qualifying norms provided by the nodal ministry of Government of India on new and renewable energy (Ministry for New and Renewable Energy) [7]. Also, the mass and energy balance was carried out for each of the test case and anomalies were corrected by performing a regression analysis based on material elemental balance.

Similarly on the engine side the qualifying parameter is related to emissions. The MNRE gasifier guidelines do not have any qualifying norms for engine emissions. Therefore the Euro II norm (stationary diesel engines) [8] that is followed by engine manufacturers in India was considered as the norm.

\subsection{Gas Composition and Calorific Value}

Figure 6 compares the calorific value of cold producer gas at maximum load or throughput. The mean calorific value of producer gas was found to be
4.5 and 4.32 MJ/kg (4.4 MJ/ $\mathrm{Nm}^{3}$ and 4.2 $\left.\mathrm{MJ} / \mathrm{Nm}^{3}\right)$ for coconut shell and cotton stalk respectively. It is evident that there is fluctuation in the gas calorific value with cotton stalk; this is attributed to some of combustible gas species burning within the reactor due to poor packing density inside the reactor. Table 3 compares the cold gas composition and calorific value of producer gas for both the feedstocks where there is evidence of marginal variation. The cold gas also contains saturated moisture corresponding to a gas temperature of about $25^{\circ} \mathrm{C}$. The Lower Calorific Value (LCV) represented in the Table is only the chemical heat and does not include the heat of vaporization. These results are consistent with the results in literature [5], which is for standard wood.

Table 2: Engine Configuration Details

\begin{tabular}{|c|c|}
\hline Engine Model & Cummins, 6B series \\
\hline \hline Bore $\times$ Stroke, $\mathrm{mm}$ & $102 \times 120$ \\
\hline Number of cylinders & 6 \\
\hline Displacement, $\mathrm{L}$ & 5.9 \\
\hline Compression ratio (CR) & $10.5: 1$ \\
\hline Aspiration & Natural \\
\hline Fuel & Producer gas \\
\hline Engine Rating, $\mathrm{kW}_{\mathrm{e}}$ & 25.0 \\
\hline
\end{tabular}

\subsection{Particulate Matter and Tar}

Table 4 shows the summary of the Particulate matter \& Tar results as a function of load and feedstock. It is evident from the results that the particulate matter in the raw gas was below 1000 
Table 3: Summary of Mean Gas Composition

\begin{tabular}{|c|c|c|c|c|c|c|}
\hline $\begin{array}{l}\text { Load, } \\
\text { kWe }\end{array}$ & $\mathrm{H}_{2}$ & CO & $\mathrm{CH}_{4}$ & $\mathrm{CO}_{2}$ & $\mathbf{N}_{2}$ & $\begin{array}{c}\mathrm{LCV}, \mathrm{MJ} / \mathrm{kg} \\
\left(\mathrm{MJ} / \mathrm{Nm}^{3}\right)\end{array}$ \\
\hline \multicolumn{7}{|c|}{ Coconut Shell } \\
\hline 12.5 & 15.6 & 20.1 & 1.7 & 10.1 & 51.9 & $4.24(4.11)$ \\
\hline 18.7 & 16.2 & 21.4 & 1.5 & 9.9 & 50.7 & $4.43(4.30)$ \\
\hline 25.0 & 16.2 & 22.2 & 1.5 & 11.0 & 49 & $4.50(4.36)$ \\
\hline \multicolumn{7}{|c|}{ Cotton Stalk } \\
\hline 12.5 & 18.0 & 18.7 & 1.7 & 12.2 & 49.5 & $4.39(4.26)$ \\
\hline 18.7 & 18.1 & 18.5 & 1.6 & 12.3 & 49.0 & $4.34(4.20)$ \\
\hline 22.0 & 17.64 & 17.67 & 1.61 & 12.2 & 49.1 & $4.32(4.19)$ \\
\hline
\end{tabular}

Table 4: Summary of Particulate Matter \& Tar Measurement

\begin{tabular}{|c|c|c|c|c|}
\hline Load, kWe & \multicolumn{2}{|c|}{ Particulate Matter $\left(\mathrm{mg} / \mathrm{Nm}^{3}\right)$} & \multicolumn{2}{|c|}{$\operatorname{Tar}\left(\mathrm{mg} / \mathrm{Nm}^{3}\right)$} \\
\hline \multicolumn{5}{|c|}{ Coconut Shell } \\
\hline & Raw Gas & Clean Gas & Raw Gas & Clean Gas \\
\hline 12.5 & 370 & 12 & 122 & 7 \\
\hline 12.5 & 464 & 7 & 115 & 16 \\
\hline 12.5 & 701 & 16 & 156 & 26 \\
\hline 18.7 & 660 & 11.0 & 139 & 8.9 \\
\hline 18.7 & 687 & 5.0 & 274 & 75 \\
\hline 25.0 & 392 & 5.0 & 221 & 12 \\
\hline 25.0 & 533 & 18 & 204 & 16 \\
\hline 25.0 & 549 & 3 & 163 & 25 \\
\hline \multicolumn{5}{|c|}{ Cotton Stalk } \\
\hline 12.5 & 557 & 15 & 305 & 37 \\
\hline 18.7 & 571 & 13 & 168 & 43 \\
\hline 22.0 & 600 & 12 & 124 & 11 \\
\hline 22.0 & 828 & 7 & 152 & 7 \\
\hline
\end{tabular}

$\mathrm{mg} / \mathrm{Nm}^{3}$ and the tar below $300 \mathrm{mg} / \mathrm{Nm}^{3}$. Similarly the particulate matter in the clean gas varied between 8 and $15 \mathrm{mg} / \mathrm{Nm}^{3}$ and the tar between 7 and $43 \mathrm{mg} / \mathrm{Nm}^{3}$, with the exception of one result with coconut shells where the tar level is about $75 \mathrm{mg} / \mathrm{Nm}^{3}$. In terms of Particulate matter \& Tar level, the results seem to be independent of the feedstock. The mean value of Particulate matter \& Tar levels at varying loads is shown in Figures 7 and 8 respectively. These values are much superior to the qualifying norms of MNRE.

\subsection{Gaseous Emissions}

Figures 9 and 10 represent the level of Carbon monoxide and NOx (including $\mathrm{NO}_{2}$ ) in the engine exhaust as a function of load and feedstock. It is obvious that the levels are below the permissible levels for Euro II norms (CO: 0.97 and NOx $1.67 \mathrm{~g} / \mathrm{MJ}$ ) for non-road diesel engines [8]. The low $\mathrm{CO}$ level is on account of clean gaseous fuel combustion and low NOx is on account of lower peak flame temperature with producer gas and air mixture [9]. Similarly the value of $\mathrm{SO}_{2}$ was well below $0.02 \mathrm{~g} / \mathrm{MJ}$ as biomass contained negligible amount of sulphur.

\subsection{Energy Balance}

All the components of energy balance, both output and input were calculated from the experimental data except for the heat loss term. The heat loss term was taken as the difference between the energy input (energy in the form of biomass) and energy output 


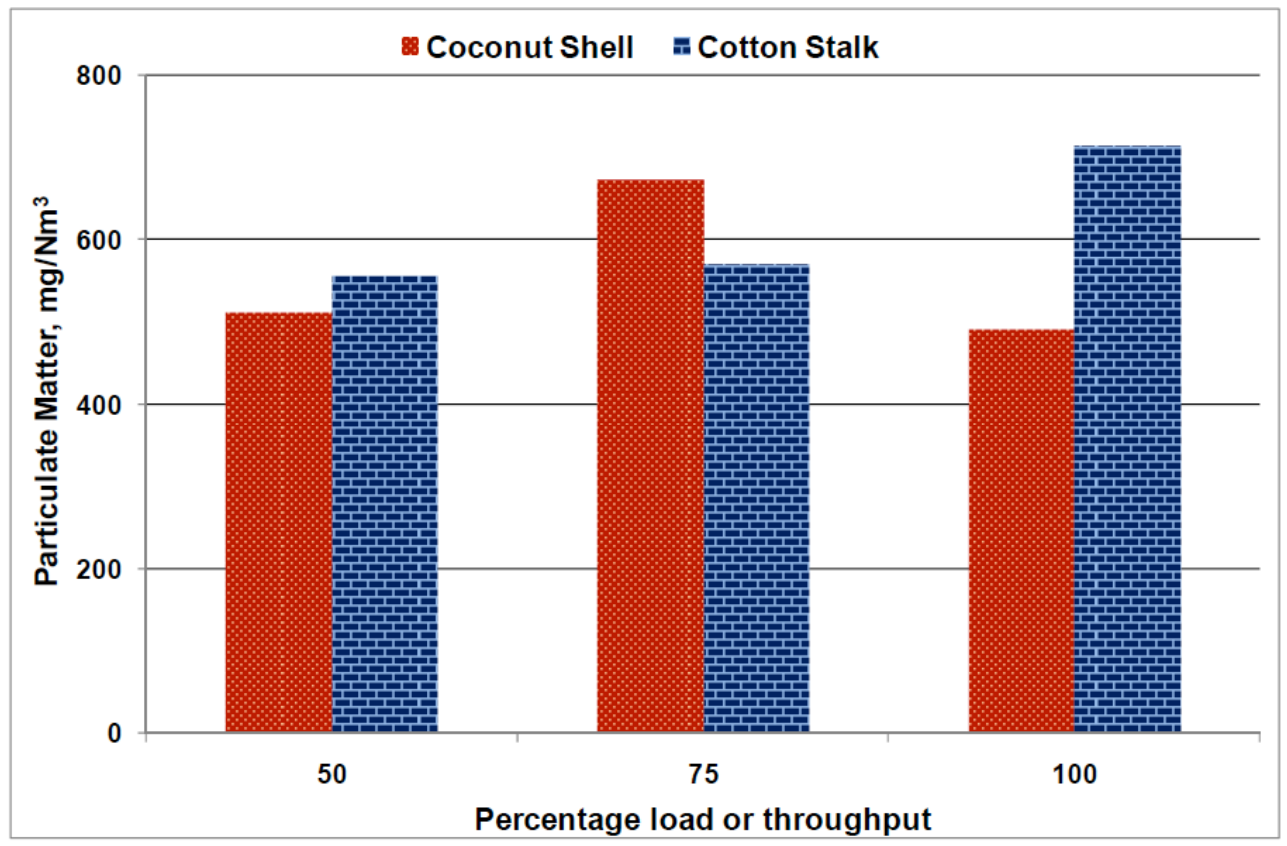

Figure 7: Particulate Matter Level in Raw Producer gas as a function of Load (mean value of multiple trials) and Feedstock.

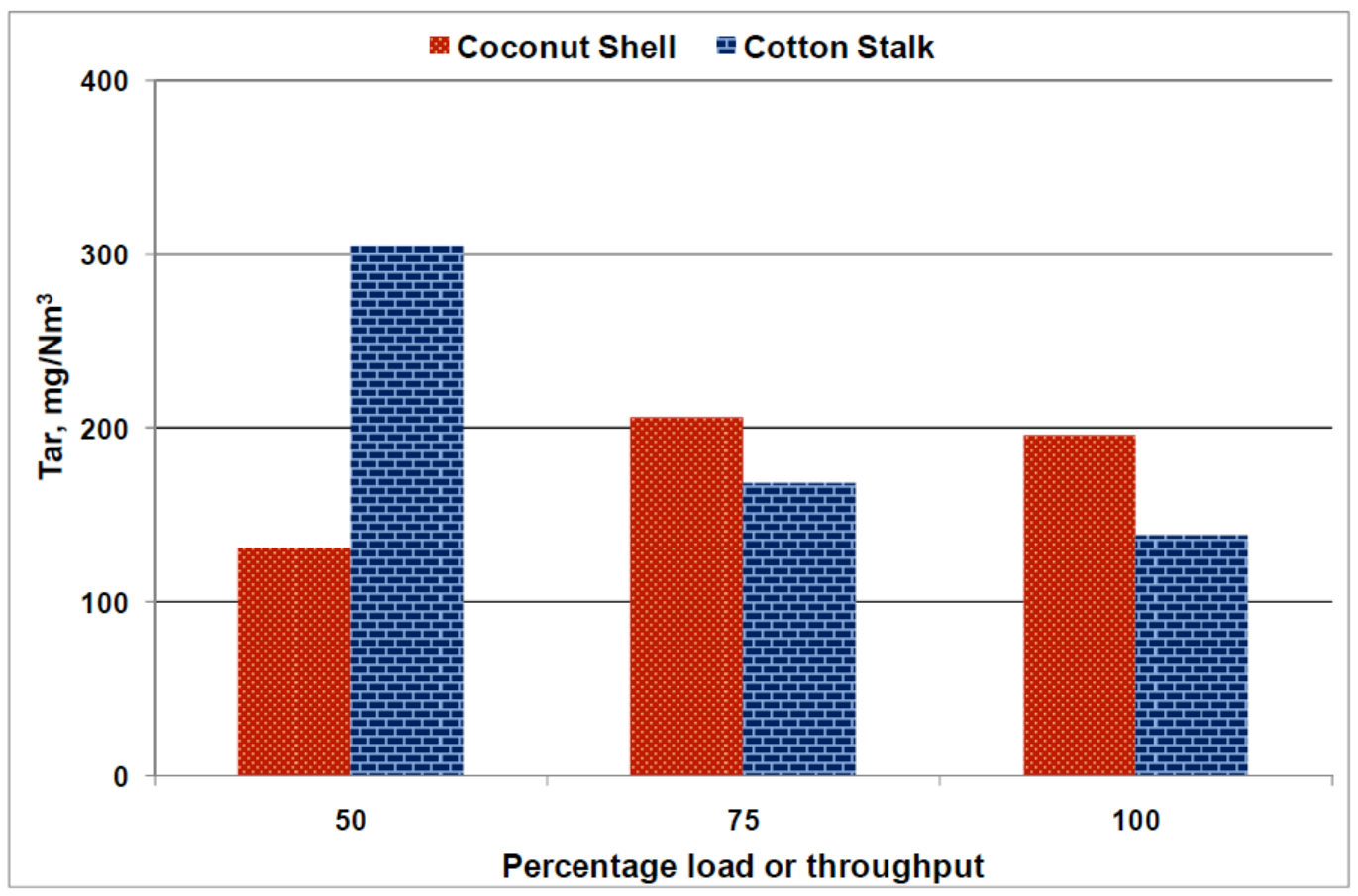

Figure 8: Tar in Raw Producer gas as a Function of Load (mean value of multiple trials) and Feedstock.

terms (energy in cold producer gas + sensible heat + latent heat + energy in char). Since the energy in Tar was very small, the same was neglected. The sensible and latent heat was estimated from the hot producer gas temperature and the water condensate collected at the raw or hot end of the particulate matter and tar sampling. For calculations, LCV of biomass, producer gas and char was considered.
Figure 11 represents the cold gas efficiency as a function of load and feedstock. The cold gas efficiency varied between 74 to $80 \%$ and 68 to $71 \%$ for coconut shell and cotton stalk respectively. This indicates that gasification efficiency is reasonably independent of load or throughput but not so with the feedstocks that has been experiemented. This will become evident if one carefully examines the energy balance for both the feedstocks. From Figure $\mathbf{1 2}$ it is evident that the heat 


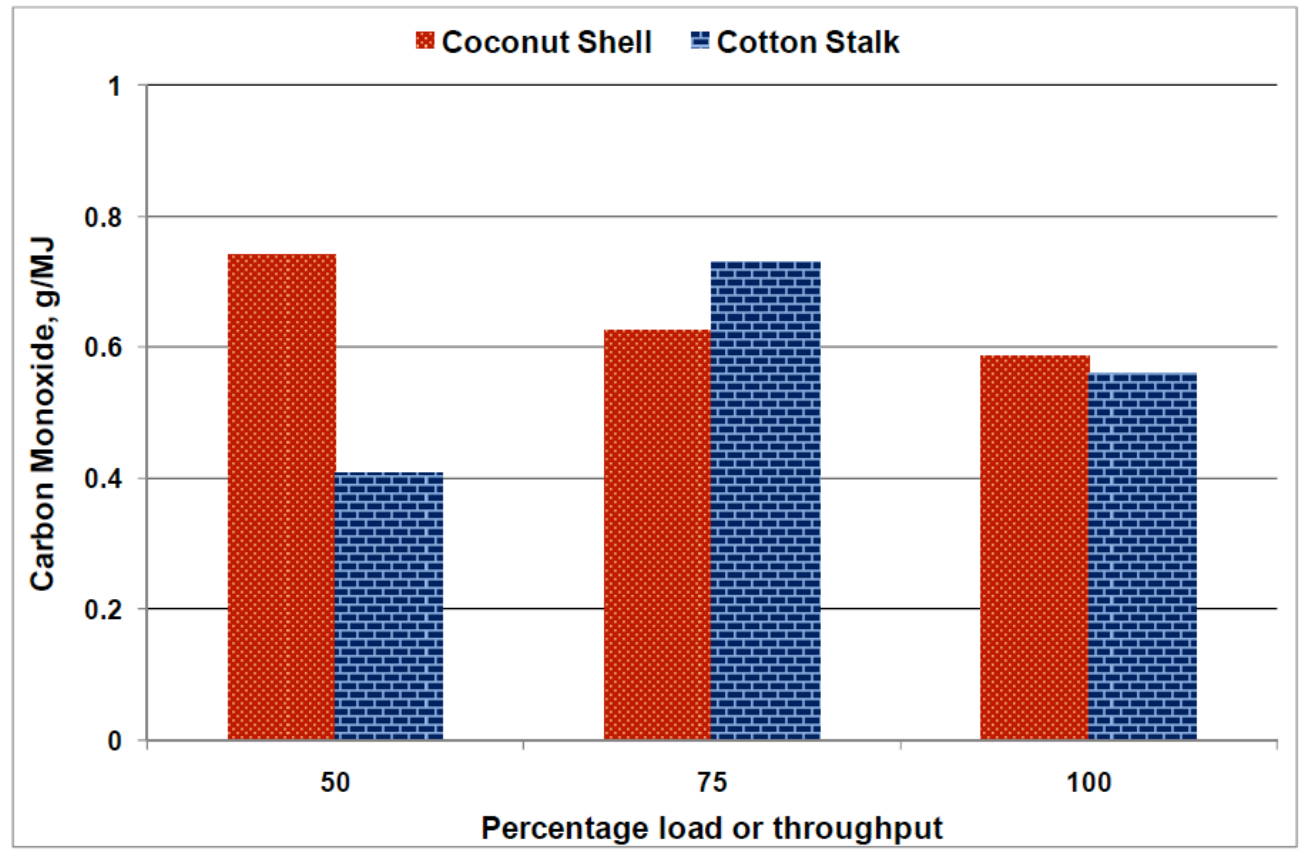

Figure 9: Carbon monoxide in the Engine Exhaust as a Function of Load (mean value of multiple trials) and Feedstock.

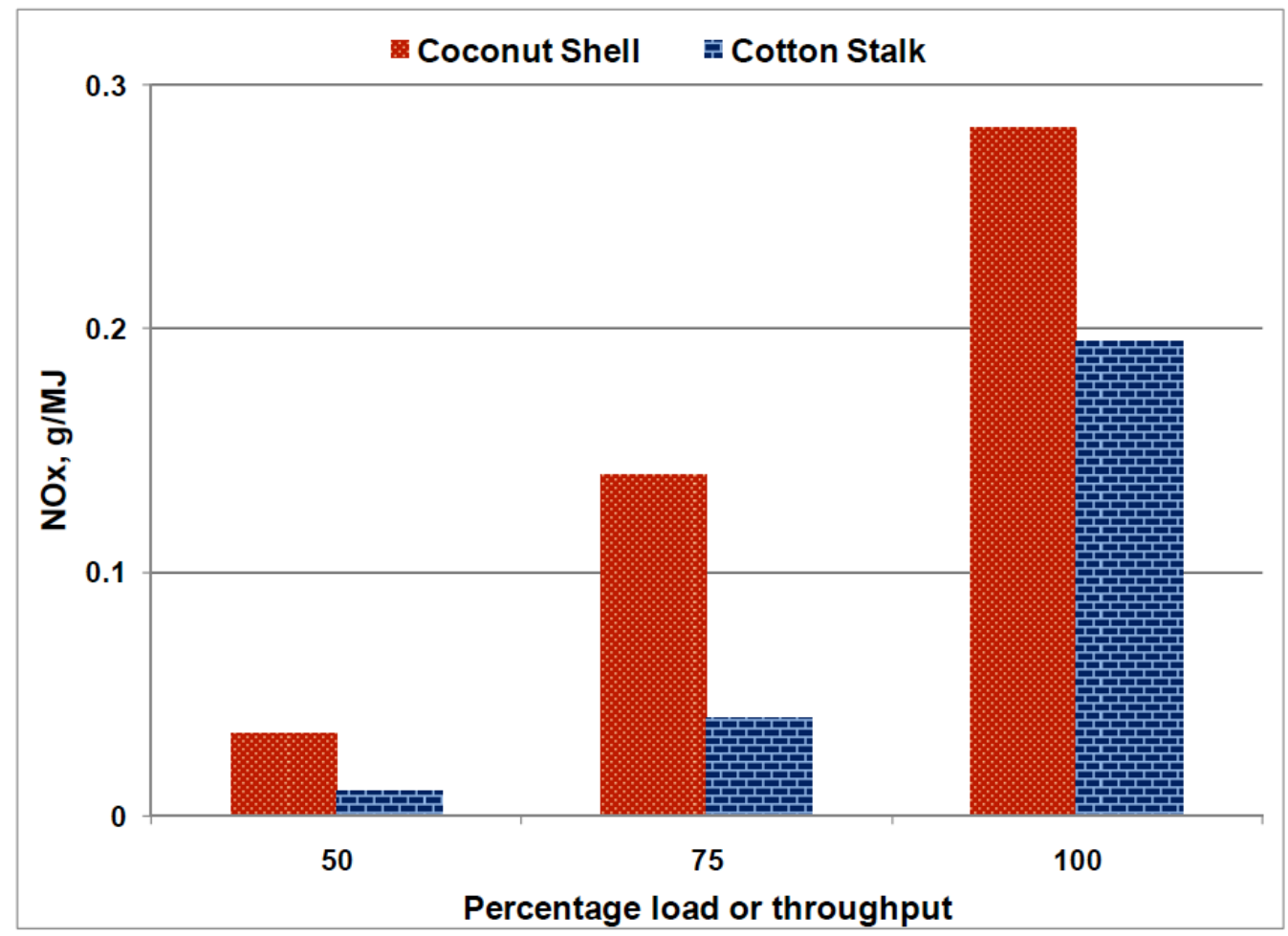

Figure 10: NOx in the Engine Exhaust as a Function of Load (mean value of multiple trials) and Feedstock.

loss in the form of sensible + latent heat is higher in case of cotton stalk than coconut shell due to higher gas exit temperature (refer Figure 5). This is attributed to improper movement of cotton stalk within the reactor, resulting in voids or gaps and thus burning of some of the combustible species of producer gas within the gasifier reactor.
The next important parameter is the specific fuel or biomass consumption (sfc). As indicated in Figure 13, the sfc varied between 1.75 to $1.3 \mathrm{~kg} / \mathrm{kWh}$ for coconut shell, for a load variation between 50 to $100 \%$. The same parameter with cotton stalk varied between 1.75 to $1.4 \mathrm{~kg} / \mathrm{kWh}$, this marginal variation is due to calorific value of producer gas being lower with cotton stalk as 


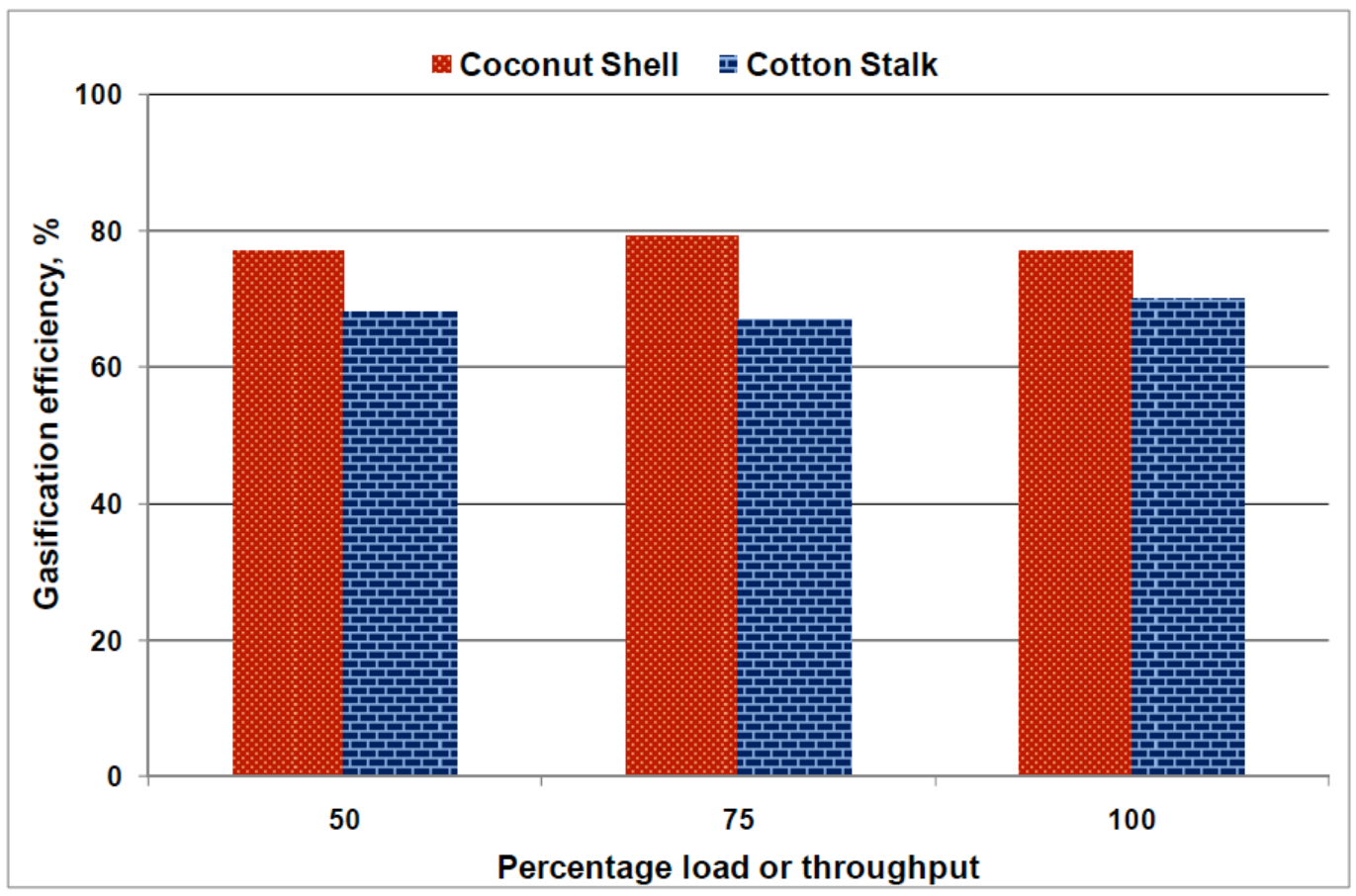

Figure 11: Gasification Efficiency (cold gas) as a Function of Load (mean value of multiple trials) and Feedstock.

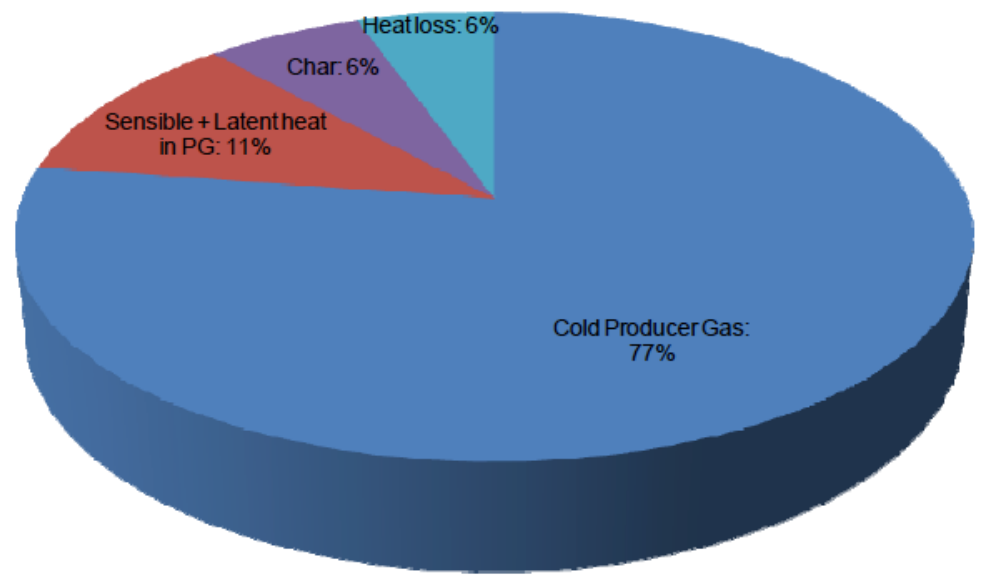

(a)

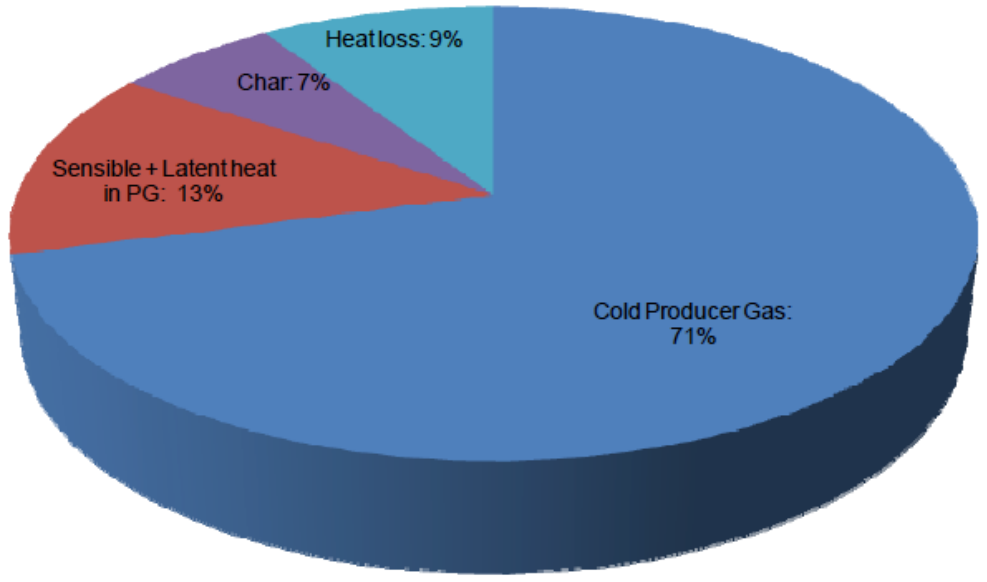

(b)

Figure 12: Energy Balance at Maximum Load (a) Coconut Shell (b) Cotton Stalk. 


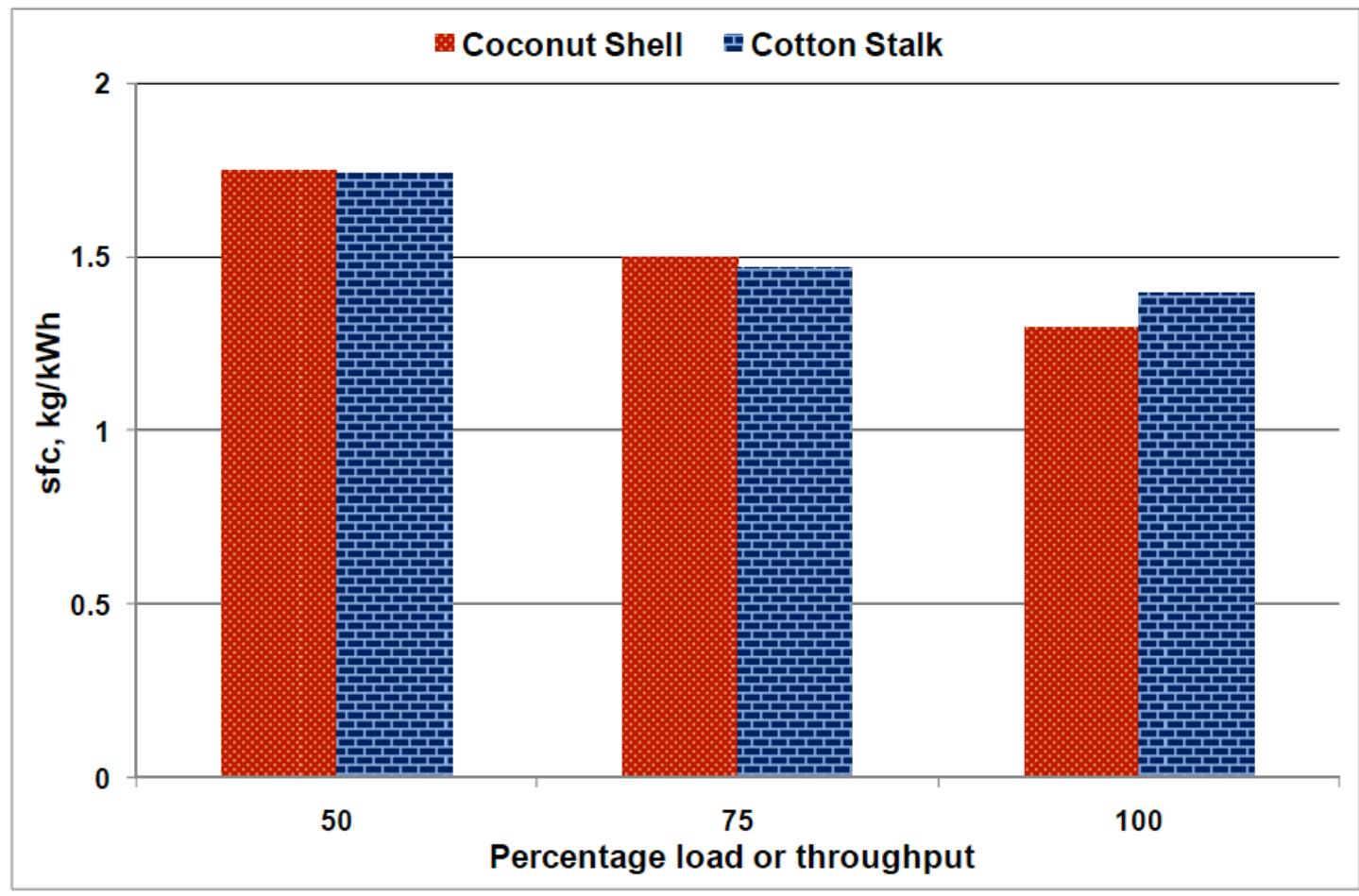

Figure 13: Specific Fuel Consumption as a Function of Load (mean value of multiple trials) and Feedstock.

compared with cotton stalk. The other reason being that higher rate of char had to be extracted with cotton stalk in order to restrict the reactor pressure drop. The values of gasification efficiency and sfc achieved are superior to the qualifying norms of MNRE [7].

\section{CONCLUSION}

In the multiple trials conducted with two vastly differing density feedstocks, the low density cotton stalk proved to be challenging in terms of operation. There were two operational issues, firstly on account of low bulk density there was poor material movement resulting in voids or gaps within the reactor; this in turn caused some producer gas to burn within the reactor resulting in higher gas exit temperature as compared to trials with coconut shells. Similarly on account of higher ash content in the cotton stalk, the char/ash had to be more frequently extracted in order to maintain the reactor pressure drop within acceptable limits. These issues resulted in lowering the maximum power output of the gas engine generator. The loss of power was to the extent of $12 \%$. Therefore these trials seems to suggest that there is lower limit of bulk density of biomass that is acceptable for gasifier operation beyond which it is necessary to resort to some form pre-processing of biomass such as briquetting or compacting. The cotton stalk, particularly in the range of less than $10-15 \mathrm{~mm}$, clearly falls under this category and would either require additional pre-processing such as briquetting or need to be mixed with higher density biomass such as wood or coconut shells.

\section{ACKNOWLEDGEMENT}

The entire work reported in this paper was carried out at Siemens Renewable Energy Innovation Centre, Bangalore and authors are thankful to Siemens Corporate Research and Technology Management for supporting this work.

\section{REFERENCES}

[1] Mukunda HS. Understanding clean energy and fuels from biomass, Wiley India Pvt Ltd, 2011.

[2] Briquetting of Crop Residues with special reference to Cotton Stalk - Market potential in India. In: Book of papers presented in the International Workshop on Utilization of Cotton Plant Residues for Value Added Products, organized by CIRCOT Mumbai, ICAC and CFC, at Nagpur during November 9-11; pp. 62-76.

[3] Pareek D, Narnaware S, Joshi A, Verma V. Gasification of crop residue briquettes in an open core down draft gasifier, $J$ Agric Eng 2011; 48(2): 2011.

[4] Dasappa S, Sridhar HV, Sridhar G, Paul PJ. Science and technology aspects of bio-residue gasification. Biomass Conver Biorefin 2011; 1(3): 121-31.

[5] Mukunda HS, Paul PJ, Dasappa S, Shrinivasa U, Sharan H, Buehler $\mathrm{R}$, et al. Results of an Indo-Swiss programme for qualification and testing of a $300 \mathrm{~kW}$ IISc-Dasag gasifier. Energy for Sustainable Development; The Journal of the International Energy Initiative 1994; 1(4).

[6] Parihar AKS, Joshi C, Sridhar G. The performance of cyclones in producer gas cleaning: experimental and modeling studies Proceedings of the Institution of Mechanical 
Engineers, Part A: Journal of Power and Energy Journal of Power and Energy 2012; 226(6).

[7] Qualifying, testing and performance evaluation of biomass gasifiers and gasifier-engine systems, Ministry of New and Renewable Energy, Govt. of India.

[8] http://www.dieselnet.com/ standards/eu/offroad.html\#s3
[9] Sridhar G, Yarasu RB. Facts about Producer Gas Engine, Paths to Sustainable Energy, Jatin Nathwani and Artie $\mathrm{Ng}$ (Ed.), ISBN: 978-953-307-401-6, InTech 2010; Available from: http://www.intechopen.com/articles/show/title/factsabout-producer-gas-engine 